\title{
The influence of Rhus coriaria seeds Extracts on the Genetic Resistance of Aspergillus amstelodami
}

La influencia de los extractos de semillas de Rhus coriaria sobre la resistencia genética de Aspergillus amstelodami

Autor:

Al-Hyaly F M ${ }^{(1)}$

Al-Rawi J M (2)
ARTÍCULO DE INVESTIGACIÓN CIENTÍFICA Y TECNOLÓGICA

How to cite this paper:

Al-Hyaly FM, Al-Rawi JM, The influence of Rhus coriaria seeds Extracts on the Genetic Resistance of Aspergillus amstelodami. Mosul, Iraq. Innovaciencia Facultad de Ciencias Exactas, Naturales y Agropecuarias. 2018; 6(1) S1: 1-9.

Reception date:

Received: 15 August 2018

Accepted: 25 November 2018

Published Online: 28 December 2018

DOI:

http:/ /dx.doi.org/10.15649/2346075X.478

\section{ABSTRACT}

Introduction: This study aims to investigate the safe use of Rhus coriaria seed extracts (water and ethanol) genetically on fungi Aspergillus amstelodami because the extensive use of plant in many pharmaceutical and food fields. Materials and methods: In this study A1 (Wa1) strain of the fungus A.spergillus amstelodami was used in all genetic testing, Rhus coriaria seeds were obtained from the local markets and two types of extracts were prepared (water and ethanol extracts of Rhus coriaria seeds), two types of resistance mutants were isolated both spontaneous and induced by using mutation agent (nitrous acid). Results and Discussion: In this study 18 spontaneous resistance mutation were isolated in frequency $4.26 \times 10-^{5}$ and 96 induced mutations were induced by nitrous acid in Frequency $39.76 \times 10-^{5}$ at (MIC) $16 \mathrm{mg} / \mathrm{ml}$ of the ethanol extract, and 22 spontaneous mutations were isolate in frequency $4.59 \times 10-^{5}$ and $91 \mathrm{ni}-$ trous acid induced mutation with an average recurrence $37.36 \times 10_{-}^{5}$ at (MIC) $25 \mathrm{mg} / \mathrm{ml}$ of water extract. Conclusion: We conclude that presence of resistant ability in $A$. amstelodami toward $R$ hus coriaria water and ethanol seeds extracts. Therefore, we suggest further thorough studies to detect the activity to plant extract in order to be use in agricultural pest control.

Keywords:

Rhus coriaria; Genetic Resistance; Aspergillus

amstelodami.

(1) Department of pharmacy, Duhok Technical Institute, University of Duhok Polytechnic, Duhok, Iraq, muna.abdelaziz@dpu.edu.krd. (2) Department of Biology, College of Science, University of Duhok, Duhok, Iraq, Mustafa.haider@uod.ac. 


\section{INTRODUCCTION}

Many organizations, including the World Health Organization (WHO), have been urged to investigate for plant extracts that are effective in the treatment of many infectious diseases as antibiotics ${ }^{(1)}$ in spite of the development of antibiotics, but many infectious diseases still considered dangerous to humans through the emergence of resistant strains resulting from a genetic mutation in the target location where the active ingredient operates ${ }^{(2)}$ therefore, the study of the genetic basis of resistance to different compounds are an important step to understanding the genetic basis of this resistance and helps to choose the right material to eliminate microorganisms. Due to the wide use of the plant of sumac in many pharmaceutical and food fields because its seeds contain active compounds such as Phenols, Tannins, Flavonoids, It has been used as an antibiotics in inhibiting the growth of fungi $\frac{(3,4,5)}{3}$ these compounds are also antibiotics for many negative and gram positive bacteria $\stackrel{(6,7)}{ }$ and inhibitory to multiply a virus Herpes simplex and Influenza virus ${ }^{(8)}$.

The plant of Sumac was known by word(Sumac) means dark red, back to the family (Anacardiaceae) (2) but the scientific name Rhus was derived from the Greek language, means "Red color", the plant of Sumac grow in the form of bushes that are automatically spread and adapted to live in different environments, It spreads in tropical temperate regions and in the Mediterranean region ${ }^{(10)}$, There are more than 250 species and the Sumac Tanning (Rhus coriaria) the most common types, the term coriaria means its use in tanning and corium means the leather, the fruits of this type are characterized by flat kidney and mauve in a reddish brown color. Sumac is considered an economically important plant, it enters into many uses, including medical and industrial as a perfume and cosmetics industry as well as a major role in tanning and dyeing leather. The fruits of sumac contain the substance Tannins, phenols and Fla- vonoids ${ }^{(6)}$ in addition to containing citric acid, acetic and malic acid, which gives it acid taste, these compounds have given the Sumac medical importance as a holding, disinfectant and anti-inflammatory, It was used as a gargle to treat the problems of mouth and throat, as well as the use of sumac extracts as a fat and anti-heat and a position for bleeding and anti-diarrhea ${ }^{(2)}$ and it was used in the treatment of burns and sores. The Aims of this study is to investigate the genetic resistance of mutations in fungus Aspergillus amstelodami towards the minimum inhibitory concentration (MIC) of the water and ethanol extract of Rhus coriaria seeds.

\section{MATERIALS AND METHOD}

\section{Test organism}

The A1 (Wa1) strain of the fungus Aspergillus amstelodami was used which was obtained from Prof. Dr. Sahi Jawad Dhahi, Science College, Department of Biology, University of Mosul.

\section{Culture media and culture conditions:}

Culture media and culture conditions were used based on the method $\stackrel{(12)}{2}$. In our present study, we used Minimal medium (M), all tests were performed on this medium plus test materials.

Complete supplement $(\mathrm{C})$ with a final concentration $5 \%$ (volume / volume) was added to the medium for supporting the growth, Sodium deoxycholate (D) with a final concentration $400 \mu \mathrm{g} / \mathrm{mL}$ also added to the medium counting the colony easily ${ }^{(13)}$.

\section{Preparation of extracts of Rhus coriaria seeds:}

1. Collecting and classifying the plant of sumac: The seeds of the plant were obtained from the local markets, Plant was classified in the Museum of Science College / Department of Biology/ University of Mosul, the seeds were cleaned of 
impurities and dust and kept in the refrigerator until the preparation of extracts.

2. Preparation of plant extracts of sumac seeds:

A. Ethanol extract: ethanolic extract was prepared based on the method described by ${ }^{(16)}$ which modified from the original method described by ${ }^{(17)}$. One gram of dry ethanol extract powder dissolved in $5 \mathrm{ml}$ of the Dimethyl sulfoxide (DMSO) to obtain a concentration of $200 \mathrm{mg} /$ $\mathrm{ml}$. the extract was sterilized by Pasteurization at $62^{\circ} \mathrm{C}$ for 20 minutes $\stackrel{(15)}{ }$. The samples were kept in freezer in glass bottles with a tight lid until they were used in the study.

B. Water extract: the seeds water extract of sumac was prepared depending on the method described by $\stackrel{(14)}{ }$. One $g$ of water extract powder dissolved in $5 \mathrm{ml}$ of distilled water to obtain a concentration of $200 \mathrm{mg} / \mathrm{ml}$, the extract was sterilized with Pasteurization at $62^{\circ} \mathrm{C}$ for 20 minutes $\stackrel{(15)}{ }$. The samples were kept frozen in glass bottles with a tight lid until they were used.

\section{Minimum Inhibitory Concentration (MIC):}

The minimum inhibitory concentration of Rhus coriaria seeds extracts (water and ethanol) was determined by using the $(\mathrm{M})$ medium containing the concentrations of each extracts separately, the concentration (0-12) $\mathrm{mg} / \mathrm{ml}$ was prepared. Then different concentrations for each plant extract was inoculated by three strains A1 of tested fungi in a plate containing $(\mathrm{M})$ medium plus a specific concentration of the studied material and three plates (R1, R2, R3) for each concentration. After four days of incubation, the colony diameters and the percentage of inhibition for each concentration were measured based on the following equation:

Percentage of inhibition $=$

\section{Preparation of spore suspension:}

The spore suspension of $A$. amstelodami was pre- pared from a four-day fresh culture incubated on the CM medium. By adding an appropriate amount of distilled water (about $10 \mathrm{ml}$ ) to the fungal culture, the spores were washed. After that the transferred to a sterile vial and shaked well to break the conidial chains, the suspension was filtered through sterile cotton to remove the Mycelial fragments and Cleistothecia, the leachate was considered as the non-dilute suspension $\left(10^{0}\right.$ dilution $) \stackrel{(12)}{\text {. }}$.

\section{Isolation of mutant resistance:}

Two types of resistance mutants were isolated, both spontaneous and induced by using mutation agent (nitrous acid) were performed, based on method described by ${ }^{(18)}$ for each extract. The spore suspension is adjusted to $10^{7}$ spore $/ \mathrm{ml}$, then mutants was tested.

\section{Isolation of spontaneous mutations:}

Dishes containing the sterilized MD medium and the appropriate concentration of the water and ethanol extract of Rhus coriaria seeds were inoculated each by $0.1 \mathrm{ml}$ prepared and adjusted spore suspension, and another 3 dishes containing the MD medium only as control were inoculated by $0.1 \mathrm{ml}$ prepared and adjusted spore suspension $\stackrel{(19)}{\text {. }}$.

\section{Isolation of induced mutations:}

The fungal suspension was treated by nitrous acid (known mutant) using the method described by (11) for this purpose 10 petri-dishes containing the MD medium and appropriate concentration of the water and ethanol extracts of Rhus coriaria seeds were inoculated, each by $0.1 \mathrm{ml} /$ spore suspension which treated with nitrous acid $\stackrel{(11)}{\longrightarrow}$ and 3 dishes containing the MD medium were inoculated by $0.1 \mathrm{~mL}$ of each adjusted spore suspention as control. The incubated for 3-4 days for control and 8-6 days for the treated plates with mutant resistance to detect their effects (19). The frequency of induced and spontaneous mutations was estimated by: 
Frequency of mutants $=\times 100$

The population size expected from the spore suspension of both treatments was estimated as follows: Size of the expected population for each treatment $=$ number of colonies on $\mathrm{MD}$ dishes $\times$ inverted dilution $\times$ number of dishes fertilized by non-dilute suspension $\left(10^{\circ}\right.$ dilution $) \stackrel{(20)}{\text {. }}$

\section{Statistical analysis:}

The mean frequency and the standard error (SE) of the mutants were calculated for each transaction. The statistical analysis of the results was performed using a t-test at a significant level of $\leq 0.05$ (21).

\section{RESULTS}

The results of the determination of the minimum inhibitory concentration (MIC) for the studied extracts, ( Tables 1,2) showed that the diameter of the A.astelodami fungi colonies decreases with increasing concentration of extracts in the medium severally, there is a positive correlation between the increasing in concentration of the extracts and the percentage of inhibition the percentage of inhibition ranged between $16.42 \%$ and $100 \%$ at concentrations 1 and 16 $\mathrm{mg} / \mathrm{ml}$ of ethanol extract, respectively, and an inhibition ratio between $16.43 \%$ and $100 \%$ at concentrations 1 and $25 \mathrm{mg} / \mathrm{ml}$ of water extract, respectively. This result indicating that the water extract of Rhus coriaria seeds has given a less inhibitory effect compared to the inhibitory effect of the ethanol extract of Rhus coriaria seeds on the growth of $A$. amstelodami which was shown in table $(1,2)$.

This result matches with the results of several studies that indicated the efficacy of the Rhus coriaria seeds as an antifungal, including the fungi under study $4^{4}$ 5.22). This activity is due to the containment of the seeds of sumac on many active compounds such as Tannins and Phenol $23,24,25)$. Which have antifungal activity against many fungi $(26,27)$.

Table 1. The effect of different concentrations of ethanol extract of Rhus coriaria on the colony diameters of $A$. amstelodami.

\section{Ethanol extract concentration $\mathrm{mg} / \mathrm{ml}$}

0

1

2

3

4

5

6

7

8

9

10

11

12

13

14

15

16
Average Colonies diameter (cm)

2.07

1.73

1.63

1.6

1.53

1.5

1.42

1.27

0.93

0.73

0.6

0.43

0.3

0.2

0.13

0.03

0
Percentage of inhibition \%

16.42

21.26

22.70

26.09

27.54

31.4

38.64

55.07

64.73

71.01

79.23

85.5

90.3

93.71

98.6

100 
Table 2. The effect of different concentrations of water extract of Rhus coriaria on the colony diameter of A.astelodami

\begin{tabular}{ccc}
$\begin{array}{c}\text { Water extract Concentrations } \\
(\mathbf{m g} / \mathbf{m l})\end{array}$ & $\begin{array}{c}\text { Average Colonies } \\
\text { diameter }(\mathbf{c m})\end{array}$ & $\begin{array}{c}\text { Percentage of inhibition \% } \\
0\end{array}$ \\
1 & 2.07 & - \\
2 & 1.73 & 16.43 \\
3 & 1.7 & 17.87 \\
4 & 1.47 & 28.99 \\
5 & 1.36 & 34.29 \\
6 & 1.3 & 37.2 \\
7 & 1.16 & 43.96 \\
8 & 1.1 & 46.85 \\
9 & 0.96 & 53.62 \\
10 & 0.86 & 58.45 \\
11 & 0.83 & 59.90 \\
12 & 0.73 & 64.73 \\
14 & 0.6 & 71.01 \\
16 & 0.43 & 79.22 \\
18 & 0.36 & 82.60 \\
20 & 0.26 & 87.43 \\
22 & 0.13 & 93.71 \\
25 & 0.03 & 98.6 \\
\hline
\end{tabular}

The current study recorded isolation of 18 the average frequency of spontaneous mutants was spontaneous mutations and 96 mutations in- $4.26 \times 10^{-5}$ while the average frequency of induced duced by nitrous acid resistant to the ethanol extract of Rhus coriaria seeds which induced by the treatment of A.astelodami fungal colony with a lower inhibitory concentration of $16 \mathrm{mg} / \mathrm{ml}$ (Table 1), and the calculation of the size of the conidial population for each treatment showed that mutants was $39.76 \times 10^{-5}$ (Table 3,4). Based on the statistical analysis the results show that there is significant differences between the mean frequency of spontaneous mutants and the nitrous acid induced mutations resistance to the extract of Rhus coriaria seeds. The calculated value of $t_{4}$ (8.236) was greater than the $t_{4}$ tabular value (4.032) at the probability level of 0.05 (Table 4). 
Table 3. The population size $\left(\times 10^{-5}\right)$ and the number of mutants (spontaneous and induced by nitrous acid) resistant to the ethanol extract $R$ hus coriaria seeds and their frequency $\left(\times 10^{-5}\right)$ observed between fungal conidia of $A$. amstelodami .

\begin{tabular}{|c|c|c|c|c|c|c|c|c|c|}
\hline \multirow[b]{2}{*}{ 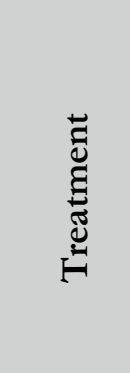 } & \multicolumn{3}{|c|}{ Average of } & \multicolumn{3}{|c|}{ Average of } & \multicolumn{3}{|c|}{ Average of } \\
\hline & 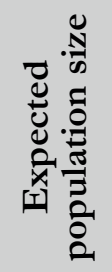 & 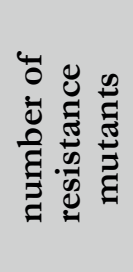 & 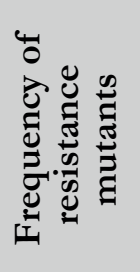 & 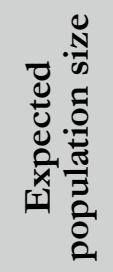 & 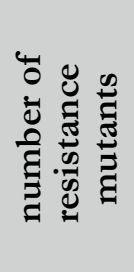 & 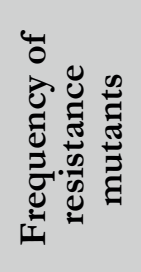 & 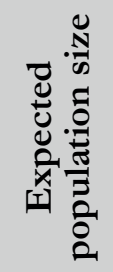 & 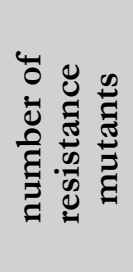 & 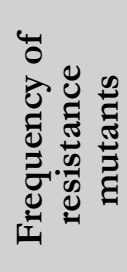 \\
\hline 0 & 118.8 & 6 & 5.0 & 179 & 6 & 3.35 & 135 & 6 & 4.44 \\
\hline $\mathrm{HNO}_{3}$ & 78.9 & 38 & 48.16 & 83.34 & 31 & 37.19 & 79.52 & 27 & 33.95 \\
\hline
\end{tabular}

0: Without treatment and their frequencies considered frequencies of spontaneous mutants. $\mathrm{HNO}_{3}$ : Treatment with nitrous acid and their frequency considered the frequencies of induced mutants.

Table (4): The average frequency of mutant (spontaneous and induced by nitrous acid) $\left(\times 10^{-5}\right)$ resistance to the ethanol extract Rhus coriaria seeds observed between fungal conidia of $A$. amstelodami.

\begin{tabular}{ccc} 
Treatment & $\begin{array}{c}\text { Average frequency of mutants } \\
\pm \text { Standard error }\end{array}$ & Calculated t4 value* \\
0 & $4.26 \pm 0.47$ & B \\
$\mathrm{HNO}_{3}$ & $39.76 \pm 4.29$ & 8.236 \\
\hline
\end{tabular}

0: Without treatment and their frequencies considered frequencies of resistance mutants. HNO3: Treatment with nitrous acid and their frequency considered the frequencies of induced mutants. *: significant at probability level 0.05 .

The results revealed that the water extract of Rhus coriaria seeds at $25 \mathrm{mg} / \mathrm{ml}$ have greater effects on the colony diameter of the $A$. amstelodami which inhibit the fungal growth completely, from the result 22 spontaneous resistance mutations and 91 nitrous acid induced mutations with average frequency of mutant $4.59 \times 10^{-5}$ and $37.36 \times 10^{-5}$ respectively (Table 5,6), the statistical analysis indicated that there is significant differences between the mean frequency of spontaneous mutants and the nitrous acid induced mutations resistance to the water extract of Rhus coriaria seeds. The calculated value of $t_{4}(18.619)$ was greater than the $t_{4}$ tabular value (4.032) at the probability level of 0.05 (Table 6). 
Table (5): The effect of water extract Rhus coriaria seeds on population size $\left(\times 10^{-5}\right)$ and the number of resistant mutants (spontaneous and induced by nitrous acid) on A. amstelodami .

\begin{tabular}{|c|c|c|c|c|c|c|c|c|c|}
\hline \multirow[b]{2}{*}{ 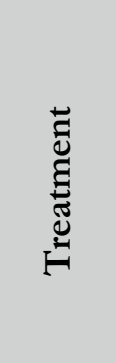 } & \multicolumn{3}{|c|}{ Average of } & \multicolumn{3}{|c|}{ Average of } & \multicolumn{3}{|c|}{ Average of } \\
\hline & 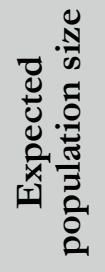 & 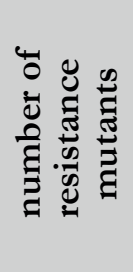 & 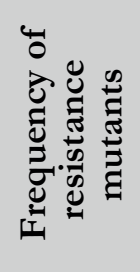 & 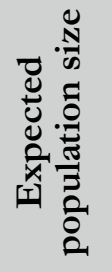 & 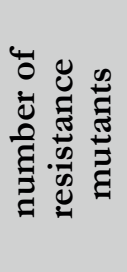 & 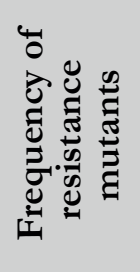 & 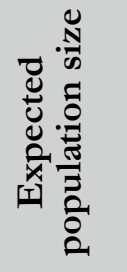 & 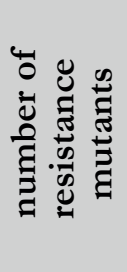 & 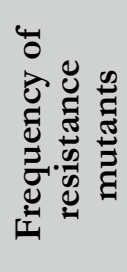 \\
\hline 0 & 170 & 8 & 4.70 & 164 & 7 & 4.26 & 145.2 & 7 & 4.82 \\
\hline $\mathrm{HNO}_{3}$ & 85.5 & 30 & 35.08 & 80.2 & 29 & 36.15 & 78.3 & 32 & 40.86 \\
\hline
\end{tabular}

0: Without treatment and their frequencies considered frequencies of resistance mutants. $\mathrm{HNO}_{3}$ : Treatment with nitrous acid and their frequency considered the frequencies of induced mutants. *: significant at probability level 0.05 .

Table (6): The average frequency of mutant (spontaneous and induced by nitrous acid) $\left(\times 10^{-5}\right)$ resistance to the water extract Rhus coriaria seeds observed between fungal conidia of $A$. amstelodami .

\begin{tabular}{ccc} 
Treatment & $\begin{array}{c}\text { Average frequency of mutants } \\
\mathbf{\pm} \text { Standard error }\end{array}$ & Calculated t4 value* \\
0 & $4.59 \pm 0.168$ & B \\
$\mathrm{HNO}_{3}$ & $37.36 \pm 1.753$ & 18.619 \\
\hline
\end{tabular}

0: Without treatment and their frequencies considered frequencies of resistance mutants. HNO3: Treatment with nitrous acid and their frequency considered the frequencies of induced mutants. *: significant at probability level 0.05 .

\section{DISCUSSION}

The results shown in the tables $(3,4,5,6$, ) indicates decrease a low frequency of spontaneous mutants compared to frequency of induced mutations resistance to both extracts , this confirmed by ${ }^{(18)}$ which

mentioned that the nitrous acid is a mutagenic factor, However, this does not negate the appearance of spontaneous mutants in the fungi $A$. amsteloda mi, which begins with a single spore, and with the doubling of the DNA and the occurrence of the divisions becomes a mutant colony resistance that spreads its spores in the air causing long-term danger especially when resisting the active compounds found in extracts of Rhus coriaria seeds which are considered important as antifungal agents in the medical field or as fungicides in the agricultural field $(22,27,28,29,30)$.

In the previous results we note that the tested fungus $A$. amstelodami was able to give strains or mutants resistant to the ethanol and water extract of the of Rhus coriaria seeds at appropriate inhibitory concentrations studied, although the number of resistance spontaneous mutants is much less than the frequen- 
cy of induced mutants and this is expected because the frequency of spontaneous mutations is very low (31, 32).

\section{CONCLUSIONS}

Rhus coriaria ethanol and water seeds extracts has inhibitory effect on $A$. amstelodami. The tested fungus A. amstelodami was able to give strains or mutants resistant to the ethanol and water extract of the of Rhus coriaria seeds at appropriate inhibitory concentrations studied, although the number of resistance spontaneous mutants is much less than the frequency of induced mutants. There is significant differences between the frequency of spontaneous mutants and the nitrous acid induced mutations.

\section{REFERENCES}

1. World Health Organisation. Summary of WHO guidelines for the assessment of herbal medicines. Herbal Gram. 1993; 28, 13-14.

2. Al-Rawi JM. The investigation about resistant mutations for thymus oil in Aspergillus amstelodami $2^{\text {nd }}$ Scientific conference for Biological ScienceSci College -Mosul University. 2011; 16 -17 Nov.

3. Abu-Reida IM, Rana MJ, Mohammed SA. Phytochemistry, pharmacological properties and industrial applications of rhus coriaria 1.(sumac). Jordan Journal of Biological Science, 2014; 7(4):233-244 .

4. Onkar S, Alia M, Akhtarb N. New antifungal xanthones from the seeds of rhus coriaria 1. J. Nat. Lib. Med. Nat. Institutes of health. 2011; 66(1-2):1723.

5. Erturk O. Antibacterial and antifungal effects of ethanolic extracts of 41 medicinal plants growing in turkey. J. Food Sci. 2010; 28(1): 53-60

6. Naaz S, Iram U, Fatima N, Rao V, Margaret E. Effect of sumac on human DNA. Inter. J. Scie. and Res. 2015; (IJSR).4(4).

7. Akrayi HFS, Abdullrahman ZFA. Screening in vitro and in vivo the antibacterial activity of rhus coriaria extract against. I.J.R.R.A.S. 2013; 15 (3):390-397.

8. Rayne S, Mazza G. Biological activities of extracts from sumac (rhus spp.) Plant Foods Hum. Nut., 2007; 62(4): 165-175 .
9. Khalilpour S, Behnammanesh G, Suede F, Ezzat MO, Muniandy J, Majid AMS, Sangiovanni E, Agli MD, Amjid AS. Neuroprotective and anti-inflammatory effect of Rhus Coriaria extract in mouse model of ischemic optic neuropathy. Biomedicines. 2018; 6(48):1-13.

10. Peter KV. Handbook of Herbs and Spices (Second Edition). 2012; 2:557-582.

11. Al-Rawi JM. Antimutagenic effect of tuber ethanolic extract of Cyperus rotandus in Aspergillus amstelodami .Journal of Rafidain Science. 2011; 22 (3), $35-45$.

12. Caten CE. Genetic determination of conidial color in Aspergillus hetero-caryoticus and relationship of this species to Aspergillus amstelodami. J. Trans. Bri. Mycol. Soc. 1979; 73: 65-74.

13. Al-Taee RKM. Effect of garlic extracts on mutagenicity of psoralen and ultraviolet ray in the fungus Aspergillus amstelodami . 2006; Master Thesis, College of Education, Mosul University, Iraq.

14. Riose JL, Recio MC, Villar A. Antimicrobial activity of selected plants employed in the Spanish Mediterranean area. J. Ethnopharmacol. 1987; 21, $139-152$.

15. Nu'man AYS. The molecular effect of some plant extracts on the growth and metabolism of some gram positive and gram-negative bacteria. 1998; Ph.D., College of Science, Mosul University, Iraq.

16. Grand A, Wondergem PA, Verpoorte R, Pousset JL. Anti-infections phytotherapies of the tree Savannah of Senegal (West-Africa) II. Antimicrobial activity of 33 species. J. Ethnopharmacol. 1988; 22: $25-31$.

17. Verpoorte R, Tginastoi A, Vandoorm $H$, Svendsen AB. Medical plant of Serinam, L-Antimicrobial activity and some medicinal plant. Ethnopharmacol. 1982; 5: $221-226$.

18. Justin K, Viateur U, Prudentienne M. Use of nitrous acid mutant of Aspergillusniger for citricacid production from local cane-molasses. J. Microbiol. Res. 2010;4 (13), 1446-1452.

19.Dahi SJ, Al-Hyaly FM. Genetics Resistance to fungicides Griseofulvin in Aspergillus amstelodami, Journal of Rafidain Science. 2006; 17 (9), 225-235.

20.Mohammad HKM. Study of the genetic effect of the antifungal Griseofulvin in Aspergillus amsteloda- 
mi. 2006; Master thesis, College of Science, Mosul University, Iraq.

21. Daoud KM, Alyaas ZA. Statistical methods of agricultural production, 1990; Higher Education Press, Mosul, Iraq.

22. Mousavi B, Rashidi A, Davari B, Zamini Q, Rahamani MR, Rezaei MA, Hosseni SV, Motahari Y. Antifungal effect of Lavandula, Salvia, Sumac, Glycyrrhiza and $\mathrm{Al}$ thoca extracts on Aspergillus species. 2012; Conference: $5^{\text {th }}$ Advances Against Aspergillosis. Istanbul, Turkey.

23. Romeo FV, Ballistreri G, Fabroni S, Pangallo S, Nicosia MGL, Schena L, Rapisarda P. Chemical characterization of different sumac and pomegranate extracts effective against botrytis cinerea rots. Molecules. J. 2015; 20: 11941-11958.

24.Krzyzowska M, Tomaszewska E, Ranoszek-Soliwoda K, Bien K, Orlowski P, Celichowski G, et al., Tannic acid modification of metal nanoparticles: Possibility for new antiviral applications. In: Andronescu, E.; Mihani Grumezescu AM, editors., editors. Nanostructures for oral medicine. New York. USA: Elsevier Inc. 2017; p.335-363.

25.Farag MA, Fayek NM, Abou Reidah I. Volatile profiling in Rhus coriaria fruit (sumac) from three different geographical origins and upon roasting as analyzed via solid-phase microextraction. Agricultural Science, Food Sci. and Technol. 2018; 3:138-150.

26. Ahmad H, Ahmad F, Hasan I, Ahmad S. Unani description of sumaq (rhus coriaria linn). And its scientific report. J. Med. Res. 2013; 13(7): 379-387.

27.Rashid TS, Hayman K, Awla HK, Sijam K. Antifungal effect of Rhus Coriaria L. fruit extracts against tomato anthracnose caused by Colletotricum acutatum . Industrial Crops \& Products. 2018; 113: 391-397.

28. Rashid TS, Sijam K, Kadir J, Halimi MS. Conference: The $12^{\text {th }}$. Asian congress on Biotechnology (ABC 2015). 2015; At Istana Hotel, Kuala Lumpur, Malaysia.

29. Anwar MA, Samaha AA, Baydoun S, Iratni R, Eid AH. Rhus coriaria L. (Sumac) Evokes endothelium- dependent vasorelaxation of rat aorta involvement of the c AMP and c GMP pathways .Front Pharmacol. J. 2018; 9:688-695.
30.Roadah M, Al-Ali AZH, Faleeha HH. The antioxidant antimicrobial of Syrian sumac (Rhus coriaria ) fruit extract . Journal of Natural Sciences Research. 2014; 4 (11) : 36 - 40.

31. Auerbach CH. Mutation Research Problems, Results and Perspectives. Springer, 1976; 452-468pp. (Chapmn and Hal/London).

32.Drake JW. The Molecular Basis of Mutation. Holden-Day, San Francisco, London, Cambridge, Amsterdam. 1970; 15(5):602-603. 